\title{
Research on Evolution of Information System and It's Implemented Economic Evaluation
}

\author{
Changhui Yang \\ School of business, Zhengzhou University \\ yang0825@126.com
}

\begin{abstract}
This paper discusses economical evaluation problem of implementing enterprise resource management systemby use of NPV method and options pricing theory, chooses basic index of evaluating project after implementing ERP/ERP II, analyses particular process of evaluating ERP/ERP II project, and evaluating enterprise final comprehensive benefit.
\end{abstract}

Keywords: NPV, Option Pricing Theory, Evaluating Index, Comprehensive Benefit

\section{Introduction}

This template provides authors with most of the formatting specifications needed for preparing their articles.

Enterprise resource management system ERP / ERP II project is the management system to maintain and develop competitive advantage and plays a major role in enterprise development, The implementation of ERP / ERP II project involves the changes of management institutional and the transformation of the way business operation, the implementation of ERP / ERP II project is also an important test of enterprise financial, material and human resources [1]. The comprehensive evaluation of ERP/ERP II project implementation is comprehensive and systematic analysis and evaluation in benefit, influence and execution in and after implementation, helps to improve investment efficiency and the level of macro decision-making and management.

\section{Evolution of Information System}

Internal mechanism of the enterprise information management system is developing and progressing in constant, MRP in the 60s, then the closed-loop MRP and MRP II, now the ERP and ERP, it has experienced five stages. Figure 1 shows the evolution process of enterprise information management system.

\subsection{Material Requirement Planning, MRP}

Based on J. A.Orlicky putting forward the independence requirements and related requirements theory, there appeared according to the time period to determine the relevant requirements of the material, this is the material requirements planning (MRP). MRP is widely used in the relevant requirements project, and achieved obvious effect in reducing inventory. Features of the MRP system cut costs by integration of MPS (Master Production Schedule) and BOM (Bill of Material, BOM) on the information, Material purchasing and Production plan.

Due to the assumptions order point method is difficult to set up in reality, so it is difficult to solve when "order" which is a core problem in inventory management. MRP is proposed to make up for the defects of the order point method, and it is a qualitative progress compared 
with order point method .It is a kind of inventory order method that can reduce inventory and prevent material shortage. MRP realized the integrated information of material, illustrated the demand for the material and plan (processing plan and purchasing plan), but it did not say if demand plan have the possibility of implementation. In other words, it put forward the demand; neither argued the possibility of implementation requirements, nor reflected the problems arising from the execution plan and the result of the execution. The main deficiency of MRP is not balance the demand and supply, and did not test whether supply can meet the demand.

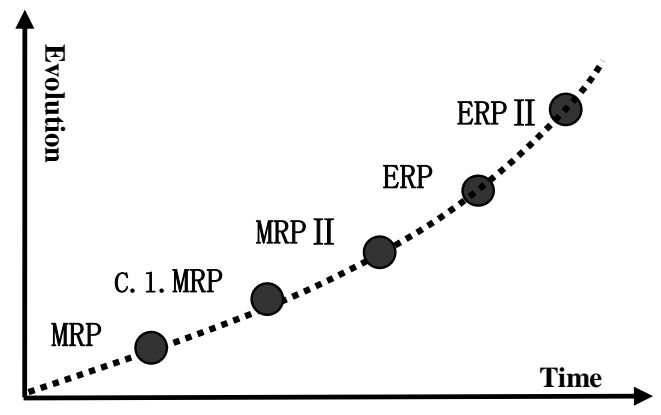

\section{Figure 1. Evolution of Information System}

\subsection{Closed-loop MRP}

MRP is called equation of manufacturing .As it doesn't take the productivity into account, when the ability is insufficient about the production plan, one may not be able to complete it, therefore, the enterprise's production capacity must be considered in, then it is likely to make feasible production plan. When production capacity is insufficient, it adjust the production plan ,then make material requirement plan again, balanced production capacity again, until the accommodation of the production plan, production capacity and material plan. So the closed loop MRP is called closed-loop MRP.

Closed loop MRP made up for the inadequacy of MRP. In this way, it have both the topdown planning information and the Executive information from bottom to top, form a closed loop information flow and business flow, then logistics can be planned and controlled. Closed loop MRP carry out the plan and make it become feasible, at the same time to speed up the speed response to environmental changes inside and outside the enterprise. But there is no clear benefits what closed-loop MRP plan execution results brought for the enterprise, because the closed loop MRP refers only to the material or "thing", that has not been linked to money.

\subsection{Material Resource Planning, MRP II}

Closed loop MRP system just have the logistics involved, but not capital flows. The separate processing of logistics and capital flow lead to repeat entering and difference of the data, what is more important is that business planning and production planning are respectively formulated and unrelated. In order to remove the unnecessary duplication of effort, reduce data inconsistency and improve work efficiency, people integrate production, finance, marketing, engineering, procurement, and other subsystems to be the integrated management system; the closed-loop MRP is called Manufacturing Resource Planning. It is also known as MRP II because it is developed from MRP. 
The essential difference of MRP II to the closed loop MRP is that the material flow which is physical form is directly converted into value flow. And it guarantees the consistency of the productive data and the financial data, realize the information integration of logistics and cash flow. MRP II system is plan leading management paradigm. It can fully mobilize the limited resources of the enterprise through careful planning; use the limited opportunities in the market to achieve corporate strategic objectives. But the MRP II is confined to the internal management of logistics, cash flow and information flow. With the global economic integration and diversified large enterprise groups, the enterprise shall be ready for the entire supply chain management, unified deploy and control the supplier, manufacturing, financial, customer. Until now the enterprise internal application of MRP II cannot satisfy the needs of the development of enterprises.

\subsection{Enterprise Resource Planning, ERP}

ERP expands the scope of control based on MRP II. ERP systems provide management function that can be effective to all links on the supply chain; these links include orders, procurement, inventory, planning, manufacturing, quality control, financial management, transportation, distribution, personnel management, etc. According to the point of system function, the ERP system added some more function subsystem than MRP II, but what is more important is close ties, cooperation and balance of these subsystems. It is these function subsystem that make all manufacturing sites, marketing system, and financial system together, so as to realize global factories, locations of multinational business operation. MRP II control the whole production process by timely rolling plan, its real-time performance is poorer, normally only realize matter controls. But ERP emphasize beforehand control ability, it can integrate design, manufacture, sales, transportation, etc., for the relevant work in parallel. So as to provide enterprises with real-time analysis capabilities about the quality, adapt to change, customer satisfaction, performance and other key problems.

Modern enterprise resource management ERP system is closely combined with the enterprise business process reengineering .It extend the scope of management information integration, realized to the entire supply chain management information integration [3], by using the computer and network communication technology, guided by the ideas of supply chain management, converging discrete production and the characteristics of the production process. Its connotation is constantly enriched with the development of information technology and management ideas.

\subsection{ERP II}

Entering the Internet age, the concept of synergy is no longer limited within the enterprise, but extends outward along the supply chain. The company's competitive advantage is not only depends on availability, cost and quality of products and services, but also depends on the quality of the information they offer partnership. So collaborative commerce emerged, its meaning is refers to the collaboration between business partners and customers which is enterprise internal and throughout the trade community, as well as the interaction process of electronic commerce. Trade community can be an industry, industry branch, the supply chain, or part of the supply chain.

Enterprises in the interests of the community (including enterprise and its suppliers, distribution network and customer, etc.,) need to release accurate information about collaborative commerce, which lead to ERP II replacing ERP as main method by which enterprises within and between can improve efficiency. ERP can not increased value in the upstream and downstream of collaborative commerce value, so it will be replaced by newer 
technology which will become the core of the enterprise business process system. In order to make the ERP processes and systems adapt to this change, users are redesigning the ERP process to include the external factors. So now a lot of ERP system is out of date in terms of structure and in the prospect of commercial application. As a result, the value basis of ERP is being changed, ERP developed into "ERP II ". Companies are beginning to transform himself from a vertically integrated organization which is focus on the internal function optimization to more flexible entities which based on the core competence, strive to make the enterprises find the best positioning in the supply chain and value network.

The evolution of the modern enterprise information management system is not over, with the progress of computer and network communication technology and the development of management thought, and the practical problems enterprises encountered in the daily operation and management activities, ERP II will evolve to the form of more complex and more advanced stages, as an enterprise information management system with openness and stability.

\section{Economical Evaluation of Implementing Enterprise Resource Management System ERP/ERP II}

\subsection{Traditional Evaluation Methods}

The economic evaluation of the implementation of ERP / ERP II system is more difficult, from the input-output point of view, you can use the technical and economic evaluation methods to evaluate the implementation of the economic benefits of ERP / ERP II system.

The NPV( Net Present Value ) is an important indicator of the dynamic evaluation of investment projects, the indicator examines the cash flows that occur each year during the life of the project. The NPV is the value that annual net cash with a certain discount rate discounts to the current cumulative value. The formula for calculating the net present value of investment projects [2]:

$$
N P V=\sum_{t=0}^{n} \frac{(C I-C O)_{t}}{\left(1+i_{0}\right)^{t}}=\sum \frac{\left(C I-K-C O^{\prime}\right)_{t}}{\left(1+i_{0}\right)^{t}}
$$

Where: NPV is the net present value; CIt is the net cash inflows in the year of $t$; COt is the net cash outflows in the year of $\mathrm{t} ; K_{t}$ is the investment spending in the year of $\mathrm{t} ; n$ is the calculation period; $i_{0}$ is the benchmark discount rate; $\mathrm{CO}^{\prime}{ }_{t}$ is the cash outflows in the year of other than investment expenditure, namely: $\mathrm{CO}_{t}^{\prime}=\mathrm{CO}_{t}-K_{t}$.

Judgment principle: For a single project, if the project is feasible economically; if the project is not feasible. When multi-plans compared to electing, using the net present value of the maximum principle, that is, the greater the net present value of the program the better the program.

The defects of the methods of Net present value evaluation: the traditional net present value evaluation methods have the inherent defects in evaluation ideas, can not evaluate the variety of development opportunities brought by the ERP project investment, the final evaluation results often underestimate the value of the project. 


\subsection{Option Pricing Theory}

In the economic evaluation of the ERP/ERP II project, to calculate the value of the project investment opportunities is a very important aspect, the use of option theory in the field of economic evaluation Investment makes up for the lack of evaluation methods of NPV, the option pricing model solves the problem successfully.

Common methods of option pricing have two kinds[3], the one is Two Item of Models, established by John C Cox, Mark Rubinstein and so on; another is the Black-Scholes Model, founded by Fischer Black and Myron Scholes.

Evaluation method based on Black-Scholes Model:

According to option pricing theory, the value of the investment opportunities of the ERP/ERP II system is actually based on the initial investment for the buyer of the agreed price options [4], the subject matter is the value of the investment projects of the ERP/ERP II system, the application of the Black - Scholes Model can calculate the value of the investment opportunities. Calculated as follows:

$\mathrm{C}$ represents the value of the buyer 's option, the Black - Scholes model is:

$$
C=S_{0} N\left(d_{1}\right)-x e^{-{ }^{r t}} N\left(d_{2}\right)
$$

Where: $S_{0}$ indicates the value of the option subject matter, here is the corresponding investment of ERP system; $x$ is the agreed price of the option; $r$ is the risk-free annual interest rate; $t$ is the maturity of the option; $\mathrm{N}\left(\mathrm{d}_{1}\right)$ and $\mathrm{N}\left(\mathrm{d}_{2}\right)$ are the cumulative probability less than that of $d_{1}$ and $d_{2}$ under normal distribution respectively, $d_{1}$ and $d_{2}$ is calculated as follows:

$$
\begin{aligned}
& d_{1}=\frac{\ln \left(s_{0} / x\right)+\left(r+\sigma^{2} / 2\right) T}{\sigma \sqrt{t}} \\
& d_{1}=\frac{\ln \left(s_{0} / x\right)+\left(r-\sigma^{2} / 2\right) T}{\sigma \sqrt{t}}=d_{1}-\sigma \sqrt{t}
\end{aligned}
$$

Where: the annual standard deviation the investment value of the relative change traditional value scope between 0.2-0.4.

ERP system investment project net present value formula based on option pricing theory can be obtained by the above formula:

NPVOPT $=$ Ttraditional $N P V+C$ (ERP system investment project contains the value of growth opportunities )

Judgment basis for: If NPVOPT $\geq 0$, then the ERP/ERP II system investment project is viable economically.

\section{Final Evaluation of Comprehensive Benefit after Implementing Enterprise Resource Management System ERP/ERP II}

\subsection{Selection of Evaluation Index}

The ultimate benefits of ERP/ERP II implementation evaluation activities should be started from the global point of view, it is necessary to consider the benefits generated by the project, but also consider the long-term benefits of the project to the enterprise development. Ultimate benefit evaluation of the ERP / ERP II project should consider the internal rate of return, 
payback period, the profit rate of investment, management level, quality of persons, administrative persons decrement [5], cost reduction rate, the rate of inventory reduction, procurement lead time shortening rate, the delayed delivery decrement, the productivity enhancement rate and so on 11 targets.

\subsection{Structure Judgment Matrix}

1. Arrangement assumes that the evaluation system including the $n$ indicators $A_{1}, A_{2}, \ldots$, $A_{n}$, the number of the experts to participate the judgment is $\mathrm{m}$.

1) To each group of indicators finds out the most important indicator and the least important indicator and determines the ratio $\mathrm{P}$ between the two.

2) Indicators of importance orders from small to large, takes the least important indicator as the datum (evaluation is 1), compares each indicator with it, carries on the evaluation according to the important degree (according to scale and standard of AHP in law). From this sort can eliminate the logical inconsistency, reduces two contrast difficulties between two, and unifies the $\mathrm{P}$ determination and various targets evaluation.

2. Synthesis evaluation method of the indicator

The evaluation that $\mathrm{m}$ experts assigned to $\mathrm{n}$ indicators divides into $\mathrm{r}$ blocks, denoted by $\mathrm{A}$ [ 1], A [2 ] , .., A [ $\mathrm{r}]$; The line of the matrix $A[k]$ is the least important indicator $A_{k}$ of the number of experts, notesm $m_{k}$, the column represents the index $A_{k}$ as a benchmark, evaluate the various indicators $A_{1}, A_{2}, \ldots, A_{n}$, assigned value. The specific form is:

$$
\mathrm{A}[\mathrm{k}]=\left[\begin{array}{cccccccc}
\mathrm{A}_{1} & \mathrm{~A}_{2} & \cdots & \mathrm{A}_{\mathrm{k}-1} & \mathrm{~A}_{\mathrm{k}} & \mathrm{A}_{\mathrm{k}+1} & \cdots & \mathrm{A}_{\mathrm{n}} \\
a_{11}^{k}, & a_{12}^{k}, & \cdots & a_{1, k-1}^{k}, & 1, & a_{1, k+1}^{k}, & \cdots & a_{1 n}^{k} \\
a_{21}^{k}, & a_{22}^{k}, & \cdots & a_{2, k-1}^{k}, & 1, & a_{2, k+1}^{k}, & \cdots & a_{2 n}^{k} \\
\vdots & \vdots & \vdots & \vdots & \vdots & \vdots & \vdots & \vdots \\
a_{m 1}^{k}, & a_{m 2}^{2}, & \cdots & a_{m, k-1}^{k}, & 1, & a_{m, k+1}^{k}, & \cdots & a_{m}^{k}
\end{array}\right]
$$

Where $a_{i k}^{k}=1,1 \leq a_{i j}^{k} \leq 9$, and $\sum_{k=1}^{r} m_{k}=\mathrm{m}\left(\mathrm{i}=1,2, \cdots, \mathrm{m}_{\mathrm{k}} ; \mathrm{j}=1,2, \cdots, \mathrm{n}\right)$.

For block matrix A [ $\mathrm{k}$ ] each index assignment let Ak as a benchmark, so Ak in average:

$$
\overline{a_{j}^{k}}=\sum_{i=1}^{m_{k}} a_{i j}^{k} / \mathrm{m}_{\mathrm{k}} \quad \mathrm{j}=1,2, \cdots, \mathrm{n}
$$

From the above formula can get row vector $\overline{A_{k}}=\left(\overline{a_{1}^{k}}, \overline{a_{2}^{k}}, \cdots, \overline{a_{n}^{k}}\right), A_{k}$ is the evaluation that $m_{k}$ experts (the least important indicator) assigned to $n$ indicators. Row vector normalization may result in the proportion of every indicator $\mathrm{A}_{\mathrm{j}}$ in $\overline{A_{k}}$ :

$$
a_{j}^{k}=\overline{a_{j}^{k}} / \sum_{j=1}^{n} \overline{a_{j}^{k}}
$$

Makes above processing to all partitioned matrix, may obtain separately $\left(\overline{A_{1}}, \overline{A_{2}}, \cdots\right.$ ,$\left.\overline{A_{r}}\right)$.

Among the evaluations that one expert give to the $n$ indexes, if the evaluations of $A_{i}$ and $A_{j}(i<j)$ are 1 , to avoid double counting, this set of data is dealt with in the block matrix $A$ [i]. 
Regarding each block matrix $\mathrm{A}[\mathrm{k}](\mathrm{k}=1,2, \cdots, \mathrm{r})$, because number of lines $\mathrm{m}_{\mathrm{k}}$ is different, the proportion in the experts $m$ is also different, thus must consider that $m_{k}$ accounts for the proportion in $\mathrm{m}$, called $\mathrm{m}_{\mathrm{k}} / \mathrm{m}$ is scaling coefficient $a_{j}{ }_{j}$.

The above analyses, the synthesis evaluation of indicator $\mathrm{A}_{\mathrm{j}}$ :

$$
\mathrm{a}_{\mathrm{j}}=\sum_{k=1}^{r} a_{j}^{k} m_{k} / \mathrm{mj}=1,2, \cdots, \mathrm{n}
$$

By the formula (5) - formula (8) can summary of $m$ experts assigned value to the $n$ indicators, obtains the final synthesis evaluation.

3. Synthesis evaluation method of ratio $P$

Find the minimum value $a_{\min }$ and maximum $a_{\max }$ from the synthesis evaluation, make the subscript are $m$ and $M$ respectively [6], that is $\mathrm{a}_{\mathrm{m}}=\mathrm{a}_{\min }, \mathrm{a}_{\mathrm{M}}=\mathrm{a}_{\max }$.

Let each row of $\mathrm{A}[\mathrm{k}]$ divide the corresponding column of $\mathrm{a}_{\mathrm{m}}$, can get

$$
A^{\prime}[k]=\left\{\begin{array}{cc}
A[k] & m=k \\
\left(\left.a_{i j}^{k}\right|_{a_{i m}^{k}} ^{k}\right)_{m \times n} & m \neq k
\end{array}\right.
$$

With the same solution method $a_{j}^{k}$, may result in $A_{m}, A_{\mathbb{N}}$, the proportion in $A^{\prime}[k]$ are

$$
\begin{aligned}
P_{\min }^{k} \text { and } P_{\max }^{k} & \\
P_{\min }^{k} & =\mathrm{m}_{\mathrm{k}} /\left(\sum_{i=1}^{m_{k}} \sum_{j=1}^{n} a_{i j}^{k} / a_{i m}^{k}\right) \\
P_{\max }^{k} & =\left(\sum_{i=1}^{m_{k}} a_{i M}^{k} / a_{i m}^{k}\right) /\left(\sum_{i=1}^{m_{k}} \sum_{j=1}^{n} a_{i j}^{k} / a_{i m}^{k}\right)
\end{aligned}
$$

With the same solution method ai, may result in Pmin and Pmax.

$$
\begin{aligned}
& \mathrm{P}_{\text {min }}=\sum_{k=1}^{r} p_{\text {min }}^{k} m_{k} / m ; \\
& \mathrm{P}_{\text {max }}=\sum_{k=1}^{r} p_{\text {max }}^{k} m_{k} / m ;
\end{aligned}
$$

Synthesis evaluation of $\mathrm{p}$ is $\mathrm{P}=\mathrm{Pmax} / \mathrm{Pmin}$.

Through above solution of ai and $\mathrm{P}$, the corresponding structure judgment matrix

$$
\mathrm{a}_{\mathrm{ij}}=\left\{\begin{array}{cc}
\frac{\left(a_{i}-a_{j}\right)(P-1)}{\left(a_{\max }-a_{\text {min }}\right)}+1 ; & a_{i} \geq a_{j} \\
1 /\left[\frac{\left(a_{j}-a_{i}\right)(P-1)}{\left(a_{\max }-a_{\text {min }}\right)}+1\right] ; & a_{i} \leq a_{j}
\end{array}\right.
$$

\subsection{Determining Important Degree Coefficient of Factors (Weight)}

According to the structure judgment matrix, calculates its maximum characteristic value $\lambda \max$, namely solve the condition to satisfy formula (15), solve the maximum value of the formula (15) $\lambda$ max: 


$$
\left|\begin{array}{cccc}
a_{11}-\lambda & a_{12} & \cdots & a_{1 n} \\
a_{21} & a_{22}-\lambda & \cdots & a_{2 n} \\
\cdots & \ldots & \cdots & \cdots \\
a_{m 1} & a_{m 2} & \cdots & a_{m n}-\lambda
\end{array}\right|=0
$$

Let the maximum characteristic root into the homogeneous equations

$$
\left\{\begin{array}{c}
\left(a_{11}-\lambda\right) x_{1}+a_{12} x_{2}+\cdots+a_{1 n} x_{n}=0 \\
a_{21} x_{1}+\left(a_{22}-\lambda\right) x_{2}+\cdots+a_{2 n} x_{n}=0 \\
\cdots \cdots \cdots \\
a_{m 1} x_{1}+a_{m 2} x_{2}+\cdots+\left(a_{m n}-\lambda\right) x_{m n}=0
\end{array}\right.
$$

Solving equation (16), so obtains the feature vectors of the maximum characteristic root $\lambda \max :$

$$
\mathrm{X}=\left(\mathrm{x}_{1}, \mathrm{x}_{2}, \cdots, \mathrm{x}_{\mathrm{n}}\right)
$$

Normalized the feature vectors obtained from formula (17) can be obtained:

$$
\mathrm{W}=\left(\frac{x_{1}}{\sum_{i=1}^{n} x_{i}}, \frac{x_{2}}{\sum_{i=1}^{n} x_{i}}, \cdots, \frac{x_{n}}{\sum_{i=1}^{n} x_{i}}\right)
$$

Let $\mathrm{W}_{\mathrm{n}}=\frac{x_{n}}{n}, \mathrm{n}=1,2, \cdots \cdots, 11$

$$
\sum_{i=1} x_{i}
$$

Then $\mathrm{W}=(\mathrm{W} 1, \mathrm{~W} 2, \cdots \cdots, \mathrm{W} 11)$, that is determining important degree coefficient of factors (weight).

\subsection{Final Evaluation of Comprehensive Benefit of ERP/ERP II Project}

The evaluating indicator altogether has 11 , collecting the data will obtain 11 target values separately to construct the target value matrix (to see formula 19):

$$
\mathrm{X}=\left[\begin{array}{cc}
X_{1} \\
X_{2} \\
\vdots \\
X_{11}
\end{array}\right]
$$

Dimensionless indicators, using extreme value method in the direct light dimensionless, the conversion formula is:

$$
\mathrm{Y}_{i}=\mathrm{X}_{i} / \max \left(\mathrm{X}_{i}\right)
$$

Where: $\mathrm{X}^{i}$ is the actual index value; $\mathrm{Y}^{i}$ is dimensionless value

Using the above dimensionless method can get the standardized indicators matrix:

$$
\mathrm{Y}=\left[\begin{array}{ll}
Y_{1} & \\
Y_{2} & \mid \\
& \mid \\
Y_{11}
\end{array}\right]
$$


Known $\mathrm{W}=\mathrm{W}=(\mathrm{W} 1, \mathrm{~W} 2, \cdots \cdots, \mathrm{Wn})$, let $\mathrm{G}=\mathrm{WY}$, there are:

$$
\mathrm{G}=\left(\begin{array}{lll}
\mathrm{W}_{1}, \mathrm{~W}_{2}, \cdots, \mathrm{W}_{\mathrm{n}}
\end{array}\right)\left[\begin{array}{l}
Y_{1} \\
Y_{2}
\end{array}\right]
$$

That is $\mathrm{G}=\sum_{j=1}^{11} W_{i} Y_{j}$

$\mathrm{G}$ is comprehensive benefit of ERP/ERP II project.

Using the above method, to determine important degree coefficient of factors (Weight) should collect data to determine the weight of index eliminate the difference index between the quantified work, then on behalf of into the appropriate mathematical evaluation model to calculate and obtain calculation results. Let the result compare with the with the original system's corresponding computed result, obtain the comprehensive benefit of ERP/ERP II project.

\section{Conclusion}

The judge of implementing enterprise resource management system ERP/ERP II is very difficult. This paper starts from the traditional evaluation method of net present value, analyzes its insufficiency, discusses economical evaluation problem of implementing enterprise resource management system (ERP/ERP II) by use of NPV method chooses basic index of evaluating project after implementing ERP/ERP II, analyses particular process of evaluating ERP/ERP II project, and analyzes how to evaluate enterprise final comprehensive benefit.

\section{Acknowledgements}

This paper was supported by NSFC (71272207, 71301150, U1304705, U1404704), NSSF 13BGL061, 10YJC630326 and 14YJC630126 (Humanity and Social Science Foundation of Ministry of Education).

This paper was sopported by Science ans Technology Research key project in Henan province department of education (No. 14A630053) and the humanity and social science research projects in Henan province department of education (2014-GH-057)

\section{References}

[1] C. H. Yang, "J. Research on Management Thoughts of ERP”, Research on Economy and Technology and Management, vol. 36, no. 5, (2002).

[2] J. J. Fu, "Economics of Industrial Technology", Qinghua University Publishing House (2000).

[3] C. C. John and M. Rubinstein, "Options Market", Prenrice-Hall Publishing House (1985).

[4] L. Glitz, "Financial Engineering", Economic Science Publishing House (1998).

[5] P. G. Wang, X. C. Guan and Q. G. Wang, "J. A Constructive Method of AHP Judgment Matrix", Theory and Practice of Systems Engineering, vol. 27, no. 8, (1998).

[6] Y. Zhang, S. P. Zhou and F. Su, "Fuzzy Mathematical Method and its Application", Coal Industry Publishing House (1991). 
International Journal of Hybrid Information Technology

\section{Author}

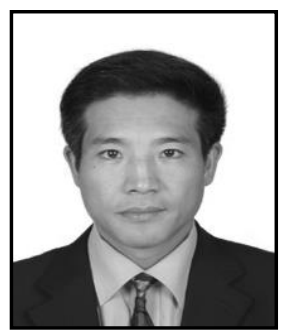

Yang Changhui, Male, Graduated from Central South University, and a doctorate in management. Now working at the business School of Zhengzhou University, The main research directions include supply chain management and management information systems. 